Received: 7 March 2019, Revised: 14 March 2019

Accepted: 8 April 2019, Published: 28 April 2019

Available online at: http://e-journal.unair.ac.id/index.php/IMHSJ

\title{
PENGARUH IMT IBU HAMIL PREEKLAMPSIA DENGAN LUARAN PERINATAL
}

\section{THE EFFECT OF PREECLAMPTIC WOMEN ON PERINATAL OUTCOMES}

\author{
Fadhilah Rahmawati ${ }^{1}$, M. Ilham Aldika Akbar ${ }^{2}$, Atika $^{2}$ \\ 1. Program Studi Pendidikan Bidan, Fakultas Kedokteran, Universitas \\ Airlangga \\ 2. Fakultas Kedokteran, Universitas Airlangga \\ Alamat Korespondensi: \\ Dusun Sumber Makmur RT 002/RW03 Sumberarum, Kec. Kerek, Kab.Tuban, Prov. Jawa \\ Timur, Indonesia \\ Email : fadhilahella82@gmail.com
}

\begin{abstract}
Abstrak
Latar belakang dan tujuan : Preeklampsia merupakan masalah komplikasi kehamilan yang menyumbang kematian ibu tertinggi di Jawa Timur. Preeklampsia dengan Indeks Massa Tubuh ibu obesitas akan meningkatkan perburukan luaran maternal dan perinatal. Penelitian ini bertujuan untuk menganalisis hubungan Indeks Massa Tubuh ibu preeklampsia dengan luaran maternal dan luaran perinatal. Metode: penelitian ini adalah analitik obsevasional dengan rancangan cross sectional, jumlah sampel 60 rekam medis ibu dan bayi baru lahir di Rumah Sakit Universitas Airlangga. Sampel terdiri dari ibu preeklampsia semua kategori IMT yaitu underweight, normal, overweight, obesitas grade I,II, dan III. Luaran perinatal yang diteliti adalah kematian perinatal, kelahiran prematur, IUGR (Intrauterine growth restriction), asfiksia, bayi berat lahir rendah, Sindrom Respiratori Distres (SRD), sepsis, Necrotizing Enterocolitis (NEC) dan Intraventrikular Hemorrhage (IVH). Hasil: Indeks Massa Tubuh Ibu preeklampsia tidak berhubungan dengan luaran perinatal antara lain kelahiran prematur, IUGR, asfiksi, BBLR dan komplikasi dini Kesimpulan: tidak ada perbedaan luaran maternal dan luaran perinatal pada berbagai Indeks massa tubuh ibu preeklampsia.
\end{abstract}

Kata Kunci : Indeks Massa Tubuh, preeklampsia, luaran perinatal

\section{Abstract}

Background and purpose : Preeclampsia is a problem of the pregnancy complications that has the highest maternal mortality in East Java. Preeclampsia with body mass index of obese mothers will increase the deterioration in maternal and perinatal outcomes. This study aims to analyze the body mass index of preeclampsia mothers with maternal and perinatal outcomes. Methods: This is an observational with cross-sectional design study, a sample of 60 pregnant women and newborn medical records at Universitas Airlangga Hospital. The sample consisted of preeclamptic women in all categories of body mass index such as underweight, normal, overweight, obesity grade I,II, and III. The perinatal outcomes observed are perinatal death, preterm birth, Intrauterine Growth Restriction (IUGR), asphyxia, low birth weight, Respiratory Distress Syndrome (RDS), sepsis, Necrotizing Enterocolitis (NEC), and Intraventricular Hemorrhage (IVH). Results: There is no significant association between body mass index of preeclampsia with perinatal outcomes. Which include preterm birth, Intrauterine Growth Restriction (IUGR), asphyxia, low birth weight and early complications Conclusion: there were no difference on maternal and perinatal outcomes in all categories Body mass index of preeclamptic women.

Keywords : body mass index, preeclampsia, perinatal outcomes 


\section{PENDAHULUAN}

Kematian seorang ibu dan bayi dalam proses persalinan atau oleh akibat lain yang berhubungan dengan kehamilan merupakan hambatan dalam pencapaian Sustainable Development Goals (SDG's) di Indonesia pada tahun 2030 dalam sektor kesehatan Goals nomor 3 yaitu menjamin kehidupan yang sehat dan mendorong kesejahteraan bagi semua orang di segala usia termasuk ibu dan bayi. Tingkat kematian ibu 99\% terjadi di negara berkembang termasuk Indonesia (WHO, 2016), dan diantara penyebab kematian ibu yang tinggi adalah preeklampsia. Preeklampsia diperkirakan secara luas menyerang 3 - 5\% kehamilan (Lapaire, 2010).

Pada Tahun 2016 masih tercatat AKI di Indonesia mencapai 4.340 jiwa dengan penyebab utama preeklampsia dan atau eklampsia sebesar 32,4\% (Kemenkes RI, 2017). Data hasil Laporan Kematian Ibu (LKI) di Provinsi Jawa Timur menempati urutan ke-3 dari 33 provinsi di Indonesia dengan jumlah kematian ibu sebanyak 534 jiwa di tahun 2016 dengan penyebab utama preeklampsia dan atau eklampsia sebesar 30,71\% (Dinkes Jawa Timur, 2017 dan Kemenkes RI, 2017). Surabaya menyumbang jumlah kematian ibu terbesar yaitu 37 jiwa tahun 2016 dengan penyebab preeklampsia dan atau eklampsia sebesar 37,84\% (Dinkes Jawa Timur, 2017).

Preeklampsia merupakan masalah obstetri utama di seluruh dunia terutama negara berkembang yang dapat menyebabkan morbiditas dan mortalitas pada ibu dan janin. Dalam Pedoman Nasional Pelayanan Kedokteran (PNPK) yang diterbitkan oleh Perkumpulan Obstetri dan Ginekologi Indonesia (POGI) (2016), preeklampsia adalah kondisi spesifik yang disebabkan oleh kehamilan, yang ditandai dengan kelainan fungsi plasenta dan reaksi maternal terhadap inflamasi sistemik, berupa hipertensi serta gangguan sistem organ pada usia kehamilan $>20$ minggu. Berdasarkan beberapa penelitian, sebagian besar faktor predisposisi preeklampsia terdapat dalam karakteristik ibu saat hamil, salah satunya overweight dan underweight (Yusrawati, 2016); dan obesitas (Witiarika, 2010).

Peluang terjadinya kejadian preeklampsia sebesar 2.5 kali sering dijumpai pada ibu yang memiliki Indeks Massa tubuh lebih dari $30 \mathrm{~kg} / \mathrm{m}^{2}$ atau obesitas. Kehamilan dengan obesitas meningkatkan risiko berbagai komplikasi yaitu 
semakin tinggi kenaikan berat badan maka semakin tinggi pula risiko timbul hipertensi gestasional dan preeklampsia pada ibu hamil (Savitri dkk, 2016). Pada penelitian Savitri dkk (2016), membuktikan bahwa status gizi berlebih dapat mengakibatkan gangguan regulasi leptin yang berdampak pada peningkatan tekanan darah. Risiko ini meningkat menjadi 13,3\% pada perempuan yang memiliki IMT lebih dari $35 \mathrm{~kg} / \mathrm{m}^{2}$. Luaran pada janin maupun bayi masalah yang terjadi berupa IUGR (intra uterine growth restriction), BBLR, asfiksia, gawat janin, kelahiran prematur, dan kematian janin.

Preeklampsia dihubungkan dengan angka mortalitas dan morbiditas maternal dan neonatal yang tinggi. Pada penelitian yang dilakukan oleh Farras di RSUD Semarang tahun 2017 dengan menganalisis faktor risiko yaitu obesitas menunjukkan bahwa ibu hamil obesitas yang menderita preeklampsia sekitar 86 orang dari $157 \mathrm{ibu}$ hamil preeklampsia mengalami peningkatan bermakna pada komplikasi berupa luaran perinatal seperti jumlah terbanyak pada kelahiran prematur (14\%), asfiksia, dan berat bayi lahir rendah. Begitu pula kejadian obesitas pada ibu hamil yang memiliki risiko luaran kurang baik untuk ibu dan juga bayinya. Di India Selatan pada periode agustus 2010- Juli 2011 dilakukan penelitian tentang efek preeklampsia terhadap ibu dan janin hasilnya 93 ibu hamil dengan preeklampsia diantaranya 44 orang atau 48,88 \% dengan IMT (Indeks Massa Tubuh) $26-30 \mathrm{~kg} / \mathrm{m}^{2}$ termasuk kategori overweight. Kategori overweight tersebut juga mempengaruhi luaran neonatal berupa kelahiran prematur sebanyak 23,65 \%, berat badan bayi lahir rendah 7,52\%, kematian perinatal $15 \%$ ( 8,6 \% kematian dalam rahim, 2,15\% kelahiran mati, dan 4,3\% kematian neonatal) (Aabidha et al, 2015).

Berdasarkan hal diatas, menunjukkan bahwa preeklampsia merupakan kejadian yang berpengaruh besar terhadap morbiditas dan mortalitas ibu maupun bayi yang dilahirkan. Dengan melihat latar belakang tersebut IMT diatas normal merupakan salah satu faktor risiko penyebab preeklampsia sehingga penelitian ini memiliki tujuan untuk menganalisis hubungan Indeks Massa Tubuh Ibu preeklampsia dengan luaran perinatal di Rumah Sakit Universitas Airlangga. 


\section{METODE}

Desain Penelitian : menggunakan analitik observasional dengan pendekatan cross sectional.

Teknik sampling : Pengambilan sampel pada penelitian ini menggunakan teknik total sampling pada populasi seluruh ibu hamil yang mengalami preeklampsia dan bersalin di RS Universitas Airlangga pada bulan Januari hingga Juni 2017.

Pengumpulan data : Data yang digunakan adalah data sekunder yang berasal dari rekam medik ibu preeklampsia yang kemudian dicatat kembali pada lembar pengumpul data

Analisa data : menggunakan uji analisis Mann-Whitney Test dengan taraf signifikasi 0,05 (5\%).

\section{HASIL DAN PEMBAHASAN}

Tabel 1 Distribusi frekuensi berdasarkan IMT ibu preeklampsia di Rumah Sakit Universitas Airlangga

\begin{tabular}{cccc}
\hline & IMT & Frekuensi & Presentase \\
\hline$<19,9$ & Underweight & 1 & $1,7 \%$ \\
$20-24,9$ & Normal & 5 & $8,3 \%$ \\
$25-29,9$ & Overweight & 24 & $40 \%$ \\
$30-34,9$ & Obesitas grade I & 21 & $35 \%$ \\
$35-39,9$ & Obesitas grade I & 7 & $11,7 \%$ \\
$\geq 40$ & Obesitas grade I & 2 & $3,3 \%$ \\
\hline Total & & 60 & $100 \%$
\end{tabular}

Tabel diatas menunjukkan sebagian besar ibu preeklampsia sejumlah 24 orang (40\%) berada dalam kategori overweight yang berarti berada dalam IMT lebih dari normal.

Tabel 2 Analisis hubungan antara IMT ibu preeklampsia dengan luaran perinatal di Rumah Sakit Universitas Airlangga

\begin{tabular}{|c|c|c|c|c|c|c|c|c|}
\hline & $\begin{array}{l}\text { Luaran } \\
\text { Perinatal }\end{array}$ & $\begin{array}{l}\text { Under- } \\
\text { weight } \\
\mathrm{n}(\%) \\
(\mathrm{n}=1)\end{array}$ & $\begin{array}{c}\text { Normal } \\
\mathrm{n}(\%) \\
(\mathrm{n}=5)\end{array}$ & $\begin{array}{l}\text { Overweight } \\
\mathrm{n}(\%) \\
(\mathrm{n}=24)\end{array}$ & $\begin{array}{c}\text { Obesitas } \\
\text { grade I } \\
\mathrm{n}(\%) \\
(\mathrm{n}=21)\end{array}$ & $\begin{array}{c}\text { Obesitas } \\
\text { grade II } \\
\mathrm{n}(\%) \\
(\mathrm{n}=7)\end{array}$ & $\begin{array}{c}\text { Obesitas } \\
\text { grade III } \\
\mathrm{n}(\%) \\
(\mathrm{n}=2)\end{array}$ & $P$ value \\
\hline 1) & $\begin{array}{l}\text { Kelahiran } \\
\text { prematur } \\
\text { a) Ya } \\
\text { b) Tidak }\end{array}$ & $\begin{array}{c}0(0) \\
1(100)\end{array}$ & $\begin{array}{c}0(0) \\
5(100)\end{array}$ & $\begin{array}{c}1(4,2) \\
23(95,8)\end{array}$ & $\begin{array}{c}1(4,8) \\
20(95,2)\end{array}$ & $\begin{array}{l}1(14,3) \\
6(85,7)\end{array}$ & $\begin{array}{c}0(0) \\
2(100)\end{array}$ & 0,409 \\
\hline 2) & $\begin{array}{l}\text { IUGR } \\
\text { a) Ya } \\
\text { b) Tidak }\end{array}$ & $\begin{array}{c}0(0) \\
1(100)\end{array}$ & $\begin{array}{l}1(20) \\
4(80)\end{array}$ & $\begin{array}{c}0(0) \\
24(100)\end{array}$ & $\begin{array}{c}0(0) \\
21(100)\end{array}$ & $\begin{array}{c}0(0) \\
7(100)\end{array}$ & $\begin{array}{c}0(0) \\
2(100)\end{array}$ & 0,105 \\
\hline
\end{tabular}


3) Asfiksia
a) $\mathrm{Ya}$
b) Tidak

$\begin{array}{cc}0(0) & 2(40)\end{array}$
$4(16,7)$
$2(9,5)$
$19(90,5)$
$\begin{array}{cc}0(0) & 1(50)\end{array}$
0,263

4) BBLR

\begin{tabular}{|c|c|c|c|c|c|c|c|}
\hline a) $\mathrm{Ya}$ & $0(0)$ & $0(0)$ & $1(4,2)$ & $1(4,8)$ & $0(0)$ & $0(0)$ & 0,948 \\
\hline b) Tidak & $1(100)$ & $5(100)$ & $23(95,8)$ & $20(95,2)$ & $7(100)$ & $2(100)$ & \\
\hline $\begin{array}{l}\text { Komplikasi } \\
\text { dini } \\
\text { a) Ya, sebab }\end{array}$ & & & & & & & \\
\hline -SRD & $0(0)$ & $0(0)$ & $0(0)$ & $3(14,3)$ & $0(0)$ & $0(0)$ & 0,064 \\
\hline -Sepsis & $0(0)$ & $1(20)$ & $8(33,3)$ & $9(42,9)$ & $5(71,4)$ & $1(50)$ & \\
\hline -lain-lain & $1(100)$ & $2(40)$ & $3(12,5)$ & $1(4,8)$ & $0(0)$ & $1(50)$ & \\
\hline b) Tidak ada & $0(0)$ & $2(40)$ & $13(54,2)$ & $8(38,1)$ & $2(28,6)$ & $0(0)$ & \\
\hline
\end{tabular}

Tabel diatas menunjukkan hasil uji variabel IMT ibu preeklampsia tidak menunjukkan hasil yang signifikan terhadap variabel kelahiran prematur ( $p$ value 0,409 ), IUGR ( $p$ value 0,105 ), asfiksi ( $p$ value 0,263 ), BBLR ( $p$ value 0,948 ), dan komplikasi dini ( $p$ value 0,064). Hasil data yang telah dikumpulkan, variabel kematian perinatal, NEC dan IVH memiliki data homogen sehingga tidak dapat dilakukan uji statistik.

\section{Hubungan antara Ibu Hamil Preeklampsia dengan Luaran Perinatal}

Kematian perinatal tidak ditemukan pada penelitian ini. Hasil tersebut sesuai dengan penelitian yang dilakukan oleh Rahmania tahun 2018 yang menyatakan bahwa asuhan atau perawatan di Rumah Sakit Unair sudah sesuai dengan target yang diharapkan. Hal ini bertentangan dengan hasil penelitian yang menunjukkan preeklampsia yang diperburuk kondisi IMT diatas batas normal akan meningkatkan insiden kematian perinatal di Australia (Dodd et al., 2014). Kematian perinatal terjadi sebab komplikasi selama kehamilan maupun dalam masa penanganan awal kehidupan neonatal (Jakarta Medical Service \& Training (JMS), 2017). Komplikasi ibu preeklampsia selama kehamilan terhadap janinnya berupa asfiksia, trauma kelahiran, infeksi, prematuritas, kelainan bawaan dan komplikasi lainnya juga dapat menyebabkan kematian perinatal (Saifuddin et al., 2010).

Menurut teori efek utama preeklampsia pada janin adalah prematuritas. kematian perinatal terkait prematuritas mencapai angka 78\%, dari jumlah kelahiran prematur tersebut, $35 \%$ diantaranya dilahirkan dari ibu yang preeklampsia (Erliana, 2016). Menurut Lamminpää (2015) obesitas pada ibu hamil meningkatkan risiko kelahiran prematur sebesar $20 \%$. 
Hasil penelitian ini menunjukkan tidak ada hubungan antara ibu preeklampsia yang overweight dengan kelahiran prematur. Hal ini didukung dengan penelitian yang dilakukan di salah satu rumah sakit di India dari bulan september 2014 hingga september 2015 menyebutkan bahwa sebagian ibu preeklampsia yang memiliki obesitas (grade I, II, dan III) hanya 2,7 \% dari seluruh luaran perinatal yang buruk yang mengalami kelahiran prematur (Prameela, 2016).

Luaran perinatal berupa IUGR tidak ditemukan pada penelitian ini. Hampir seluruhnya ibu preeklampsia tidak memiliki komplikasi ini. Hal ini bertentangan dengan teori ada preeklampsia adanya daerah pada arteri spiralis yang memiliki resistensi vaskular disebabkan oleh karena kegagalan invasi trofoblas ke arteri spiralis pada tahap ke dua. Akibatnya, terjadi gangguan aliran darah di daerah intervilli yang menyebabkan penurunan perfusi darah ke plasenta. Hal ini dapat menimbulkan iskemik dan hipoksia di plasenta yang berakibat terganggunya pertumbuhan bayi intra uterin (IUGR) hingga kematian bayi (Cunningham et al., 2014).

Hasil penelitian ini ditemukan bahwa IMT ibu preeklampsia overweight dan obesitas tidak memiliki hubungan yang signifikan dengan komplikasi asfiksia. Meskipun, sebagian besar persalinan yang terjadi adalah persalinan perabdominal. Hal ini bertentangan dengan penelitian yang dilakukan Fanny bahwa Bayi yang lahir dari persalinan perabdominal memiliki 2,6 kali untuk mengalami asfiksia dan 3,9 kali saat keadaan emergensi. Hal tersebut disebabkan perubahan tekanan perfusi dan resistensi vaskuler akibat anaestesi pada persalinan perabdominal. Kompresi dada tidak dilakukan ketika paru-paru bayi yang lahir perabdominal mengandung lebih banyak cairan selama 6 jam pertama kehidupan (Fanny, 2015).

Penelitian yang dilakukan oleh Minardo tahun 2014 menyebutkan bahwa risiko asfiksia bayi baru lahir hanya ditemukan pada ibu primitua sekunder dengan umur >35 tahun karena berkurangnya elastisitas otot sehingga proses persalinan cenderung sulit. Pada penelitian ini tidak ditemukan risiko asfiksia pada bayi baru lahir karena rata-rata ibu preeklampsia yang overweight atau obesitas sebagian besar berada pada rentang umur 20-34 tahun dan multigravida. 
Hasil penelitian ini menunjukkan bahwa IMT ibu preeklampsia Overweight atau obesitas tidak memiliki hubungan yang signifikan dengan komplikasi BBLR. Hal tersebut tidak sesuai dengan penelitian yang dilakukan di Indonesia yang menyebutkan bahwa ibu preeklampsia memiliki kemungkinan 2,7 kali untuk melahirkan BBLR (Balaka, 2017).

BBLR dapat terjadi sebab gangguan nutrisi janin akibat perfusi plasenta yang berkurang sehingga terjadi spasme pembuluh darah kemudian menganggu sirkulasi uteroplasenta (Fraser \& Cooper, 2009; Saifuddin et al., 2010). BBLR merupakan faktor risiko independen yang artinya tidak dapat berdiri sendiri tanpa ada faktor risiko lain yang mendukung. Faktor risiko BBLR merupakan gabungan dari faktor $\mathrm{ibu}$, faktor plasenta dan faktor janin. Hasil penelitian ditemukan hal yang berbeda. IMT ibu merupakan faktor minor BBLR (Jakarta Medical Service \& Training (JMS), 2017). Penjelasan tersebut dapat ditarik kesimpulan bahwa IMT pada ibu preeklampsia bukan merupakan satu-satunya faktor penyebab BBLR.

Hasil penelitian ini menunjukkan tidak ada hubungan yang signifikan antara ibu preeklampsia yang overweight atau obesitas dengan luaran perinatal berupa SRD. Data yang ditemukan dari penelitian ini hanya sebagian kecil perinatal yang mengalami SRD. Faktor penyebab dari SRD sendiri salah satunya adalah bayi prematur dan BBLR, sedangkan data yang ada menyebutkan bahwa sedikit dari perinatal yang mengalami kondisi lahir prematur ataupun BBLR (Dwiristyan et al. 2015).

Terdapat upaya pencegahan dalam mengurangi kejadian SRD yaitu Skrining faktor risiko, rujukan berencana dan terapi kortikosteroid pada janin. Pemberian terapi kortikosteroid dapat meningkatkan sintesis fosfolipid surfaktan pada sel pneumosit tipe II sehingga meningkatkan maturitas paru (Ayu \& Sari, 2017).

Sepsis dapat terjadi karena kondisi neutropenia atau penurunan umur neutropil dari 6,3 jam menjadi 4 jam yang mengakibatkan produksi sitokinin terhambat. Produksi sitokinin yang terhambat berakibat terhadap habisnya cadangan neutrophil sehingga memudahkan bakteri untuk tumbuh dan berkembang biak. Salah satu penyebab neutropenia adalah preeklampsia (Nurfianto, 2004). Hasil yang ditemukan pada penelitian ini tidak menunjukkan hasil yang signifikan 
terhadap komplikasi dini berupa sepsis. Hal ini didukung oleh penelitian yang dilakukan Wilar et al.(2010) dimana yang menjadi penyebab atau faktor yang paling berpengaruh dari sepsis adalah prematuritas, bayi berat lahir sangat rendah (1000-1500 gram) dan asfiksia. Data yang diperoleh tidak menyebutkan adanya faktor-faktor lain yang muncul seperti yang disebutkan.

Kelainan yang ditandai dengan nekrosis usus pada bayi prematur yang menghasilkan morbiditas dan mortalitas yang signifikan dan 1 Sekitar 7\% bayi dengan berat lahir antara 500 dan 1500 g mengalami NEC (Tanner et al, 2015). Data yang ditemukan dari luaran perinatal ibu preeklampsia tidak ada yang menderita NEC sehingga data homogen yang didapat maka tidak bisa dilakukan perhitungan. Sampai saat ini belum ada penelitian terkait yang membahas dampak IMT obesitas ibu preeklampsia terhadap luaran perinatal berupa NEC. Risiko NEC meningkat pada IUGR karena penurunan aliran darah yang mengandung nutrisi untuk pertumbuhan. Penurunan aliran darah dikarenakan adanya vasokontrisi sebagai akibat hipoksia intrauterin yang sering terjadi pada janin dari ibu preeklampsia (March et al., 2014).

Komplikasi perinatal berupa IVH (Intraventricular Hemorrhage) tidak ditemukan pada seluruh ibu preeklampsia dalam penelitian ini, sehingga data yang diperoleh bersifat homogen dan tidak dapat dilakukan uji korelasi. Faktor mayor penyebab IVH pada perinatal bukan hanya preeklampsia. Tetapi, gabungan faktor lain yang dapat menyebabkan IVH seperti risiko persalinan prematur, asfiksia dan RDS yang diperburuk dengan adanya preeklampsia. Tiga faktor tersebut merupakan faktor mayor atau dominan untuk dapat memunculkan IVH (Szpecht et al., 2016). penelitian yang ada saat ini belum menjelaskan hubungan IMT ibu preeklampsia yang obesitas dengan luaran perinatal IVH.

Berdasarkan hasil beberapa luaran perinatal yang ditemukan dalam penelitian ini sebagian besar menunjukkan luaran perinatal yang buruk pada ibu preeklampsia dengan obesitas. Penelitian yang mendukung hasil ini adalah penelitian oleh Dodd (2014) menyebutkan komplikasi perinatal yang dapat muncul seperti kematian perinatal, makrosomia, perawatan bayi intensif, penyakit kuning atau jaundice dan hipoglikemi yang butuh perawatan lebih. Penelitian yang lain menurut Khalil et al. 
(2013) luaran perinatal yang buruk juga dipengaruhi oleh karakteristik ibu yang memiliki IMT diatas batas normal. Peran bidan dalam menurunkan luaran bayi baru lahir yang buruk dapat dengan melakukan upaya pelayanan kesehatan yang bermutu yaitu antenatal care (ANC). pelayanan tersebut diberikan pada fasilitas kesehatan tingkat pertama di masyarakat.

\section{SIMPULAN DAN SARAN}

Berdasarkan hasil penelitian dapat disimpulkan Indeks Massa Tubuh Ibu preeklampsia tidak berhubungan dengan luaran perinatal di Rumah Sakit Universitas Airlangga. Saran untuk RS Universitas Airlangga adalah pelayanan dan fasilitas kesehatan yang sudah optimal diharapkan mampu dipertahankan sebab hasil luaran maternal dan perinatal pada ibu preeklampsia tergantung pada kualitas pelayanan, kemudian saran untuk tenaga kesehatan yang bertugas adalah diharapkan mampu mempertahankan dan meningkatkan kualitas skrining atau deteksi dini preeklampsia yang telah dilakukan untuk kedepannya, serta untuk peneliti selanjutnya diharapkan bisa melakukan penelitian dengan menggunakan desain penelitian yang berbeda dengan penelitian ini. Menambahkan variabel lain dan sampel yang proporsional.

\section{DAFTAR PUSTAKA}

Aabidha, P. M., Cherian, A. G., Paul, E., \& Helan, J. (2015). Maternal and fetal outcome in pre-eclampsia in a secondary care hospital in South India. Journal of family medicine and primary care, 4(2), 257-260. doi:10.4103/2249-4863.154669[online]. Diperoleh dari http :// jfmpc.com (diakses pada 28 Januari 2019).

Ayu, R. dan Sari, R. D. P. (2017) Peran Kortikosteroid dalam Pematangan Paru Intrauterine. Medical Journal of Lampung University, [online] 6 (3), hlm. 142-147. Diperoleh dari: http://juke.kedokteran.unila.ac.id/index.php/majority/article/view/1125/97 $\underline{2}$ [diakses pada 11 Juni 2019].

Balaka, S. N. (2017) Hubungan Preeklampsia dengan Bayi Berat Lahir Rendah (BBLR) di Rumah Sakit Umum Bahteramas Provinsi Sulawesi Tenggara Tahun 2016. Skripsi. Politeknik Kesehatan Kendari. Diperoleh dari: $\quad$ http://repository.poltekkes-kdi.ac.id/73/ [diakses pada 12 Juni 2019]

Cunningham, Gary.,Leveno, Bloom., et al. (2014). Obstetri Williams edisi 23 volume 2. Jakarta : EGC. 
Dinkes Provinsi Jawa Timur. (2017). Profil kesehatan Jawa Timur. Surabaya : Dinas Kesehatan Provinsi Jawa Timur.

Dood, J. M., Turnbull, D., McPhee, A. J., Deussen A. R., Grivell, R. M., Yelland L. N., Crowther A. A., Wittert G., Owens, J. A. dan Robinson J. S. (2014) Antenatal Lifestyle Advice for Women Who are Overwight or Obese: Limit Randomised Trial. BMJ, [online] 30 (3) hlm. 1-12. Diperoleh dari: https://www.bmj.com/content/bmj/348/bmj.g1285.full.pdf [diakses pada 15 Juni 2019].

Dwiristyan, F., Sarosa, G. I., Rini, A. E. (2015) Faktor Risiko Penyakit Membran Hialin Pda Bayi Berat Lahir Rendah. Media Medika Muda, [online] 4 (4), hlm. 772-780. Diperoleh dari:

https://ejournal3.undip.ac.id/index.php/medico/article/view/9742/9463 [diakses pada 10 Juni 2019].

Erliana. (2016). Hubungan Antara onset Preeklampsia berat, waktu terminasi dan komplikasi ibu dengan luaran neonatal pada preeklampsia berat perawatan konservatif. Tesis. Universitas Airlangga Surabaya.

Fanny, F. (2015) Sectio Caesarea sebagai Faktor Risiko Kejadian Asfiksia Neonatorum. Medical Journal of Lampung University, [online] 4 (8) hlm. 57-61. Diperoleh dari: http://juke.kedokteran.unila.ac.id/index.php/majority/article/view/1474/13 13 [diakses pada 8 Mei 2019].

Farras, R. M. (2017). Luaran Maternal Dan Perinatal Pada Ibu Hamil Dengan Preeklampsia Di RSUD Semarang Tahun 2015 (Analisis Faktor Risiko Obesitas). Tesis. Fakultas Kedokteran Universitas Negeri Diponegoro.

Fraser, D. M. and Cooper, M. A. (2009) Myles Buku Ajar Bidan. 14th ed. Diterjemahkan oleh: Rahayu, S., Mahmudah L., Yosephin, M. P., Ariani, $\quad$ F., Yoseph, A., Rohana, Imami N. dan Eka, Wilda. Jakarta: EGC, hlm. 351- 365.

Jakarta Medical Service \& Training (JMS). (2017) Pelatihan Penanganan Gawat Darurat Obstetrik Neonatal JEMS 119. Jakarta: Jakarta Medical Service \& Training (JMS), hlm. 54-68.

Kementrian Kesehatan Republik Indonesia. (2017). Profil kesehatan Indonesia 2014-2016. Jakarta: Kementrian Kesehatan RI.

Khalil, A., Syngelaki, A., Maiz N, Zinevich, Y dan Nicolaides, K. H. (2013) Maternal Age and Adverse Pregnancy Outcome: A Cohort Study. Ultrasound Obstet Gynecol, [online] 42 (6), hlm. 634-643. Diperoleh dari: https://obgyn.onlinelibrary.wiley.com/doi/epdf/10.1002/uog.12494 [diakses pada 26 Juni 2019].

Lamminpää, R. (2015) Advanced Maternal Age, Pregnancy and Birth. Disertasi.University of EasternFinland. Diperoleh dari: http://epublications.uef.fi/pub/urn isbn 978-952-61-17102/urn_isbn_978-952-61-1710-2.pdf [diakses pada 10 April 2019].

Lapaire, Olav. (2010). Preeclampsia diagnosis, Prevention, and Treatment. University Hospital Basel: SGAR Satellite Meeting.

March, M. I., Gupta, M., Modest, A. M., Wu, L., Hacker, M. R., Martin, C. R. dan Rana, S. (2014) Maternal Risk Factors for Neonatal Necrotizing 
Enterocolitis. J Matern Fetal Neonatal Med, [online], 7 (27), hlm. 1-6. Diperolehdari:https://www.ncbi.nlm.nih.gov/pmc/articles/PMC4457698/p df/nihms-694575.pdf [diakses pada 3 Maret 2019].

Minardo, J., Sari, K., Susilowati, T. (2014) Analisis Faktor-Faktor Penyebab Kematian Bayi dengan Asfiksia di Kabupaten Semarang. Skripsi.

Akademi Keperawatan Ngudi Waluyo. Diperoleh dari: https://jurnal.unimus.ac.id/index.php/psn12012010/article/view/1201/1254 [diakses pada 3 Mei 2019].

Nurfianto, S. (2004). Luaran Neonatal Preterm pada Kasus Preeklampsia. [online] etd.repository.ugm.ac.id. Diperoleh dari: http://etd.repository.ugm.ac.id/index.php? $\bmod =$ penelitian detail\&sub $=\mathrm{Pe}$ nelitianDetail\&act $=$ view\&typ $=$ html\&buku_id=25246 [diakses pada 25 Mei 2019].

Perkumpulan Obstetri Ginekologi Indonesia (POGI). (2016). Pedoman nasional pelayanan kedokteran: diagnosis dan tata laksana pre-eklampsia. Himpunan Kedokteran Feto Maternal. Diakses dari http://pogi.or.id/publish/download/pnpk-dan-ppk/ pada 26 November 2018.

Prameela H. J., Madhuri S. (2016). Obesity in pregnancy : maternal and perinatal outcome. International Journal of Reproduction, Contraception, Obstetrics and Gynecology Prameela HJ et al. Int J Reprod Contracept Obstet Gynecol. 2017 Jan;6(1):141-144. Diperoleh dari https://www.ijrcog.org/index.php/ijrcog/article/view/652/600(diakses pada 5 Juli 2019).

Saifuddin, A. B., Rachimhadhi, T., Wiknjosastro. G. H. (2010). Ilmu kebidanan sarwono prawirohardjo. Jakarta : PT Bina Pustaka Ed 4, Cet 3.

Savitri, A. I., Zuithoff, P., Browne, J. L., Amelia, D., Baharuddin, M., Grobbee, D. E., \& Uiterwaal, C. S. (2016). Does pre-pregnancy BMI determine blood pressure during pregnancy? A prospective cohort study. BMJ open, 6(8), e011626. doi:10.1136/bmjopen-2016-011626

Szpecht, D., Szymankiewicz, M., Nowak, I. dan Gaszinowski, J. (2016) Intraventricular Hemorrhage in Neonates Born Before 32 Weeks of Gestation-Prespecive Analysis of Risk Factors. Springer, [online] 32 (8), hlm 1399-1404. Diperoleh dari: https://link.springer.com/content/pdf/10.1007\%2Fs00381-016-3127-x.pdf [diakses pada 1 Juni 2019].

Tanner, S. M., Berryhill, T. F., Ellenburg, J. L., Jilling, T., Cleveland, D. S., Lorenz, R. G. dan Martin, C. A. (2015) Pathogenesis of Necrotizing Enterocolitis. The American Journal of Pathology, [online] 185 (1), hlm. 4-16. Diperoleh dari:

https://www.ncbi.nlm.nih.gov/pmc/articles/PMC4278236/pdf/main.pdf [diakses pada 17 Februari 2019].

Wilar, R., Kumalasari, E., Suryanto, D. Y. dan Gunawan, S. (2010) Faktor Risiko Sepsis Awitan Dini. Sari Pediatri, [online] 12 (4), hlm 265-269. Diperoleh dari https://saripediatri.org/index.php/saripediatri/article/view/504 [diakses pada 20 Juni 2019].

Wittiarika, I. D. (2010). Hubungan antara tingkat indeks masa tubuh (IMT) dengan kejadian preeklampsia. Skripsi. Universitas Airlangga Surabaya. 
World Health Organization (WHO). (2016). Media center (maternal mortality). Diakses dari http://www.who.int/mediacenter/factsheets/fs348/en/ pada 15 November 2018.

Yusrawati, Saputra, N., Lipoeto, N. I., \& Machmud, R. (2017). Analyses of Nutrients and Body Mass Index as Risk Factor for Preeclampsia. Journal of obstetrics and gynaecology of India, 67(6), 409-413. doi:10.1007/s13224017-0982-7[dipublikasi pada 24 Maret 2017]. 